\title{
EFFECT OF WASTE MATERIALS ON CALIFORNIA BEARING RATIO FOR GRANULAR BASE
}

\author{
*Jleel H. Rasheed ${ }^{1}$
}

\author{
Zainab A. Alkaissi ${ }^{1}$
}

\author{
Hanan A. Hassan ${ }^{1}$
}

1) Highway and Transportation Engineering Department, College of Engineering, Mustansiriyah University, Baghdad, Iraq

\begin{abstract}
It is known that paving is a system with multiple layers and the strength of each layer is reflected on the entire pavement. Two kinds of materials are used as the base layer, and the materials are divided into ordinary traditional granular materials and recycled materials such as foundry sand. This paper presents the results of laboratory tests in the laboratory and discusses the effect of each of the materials and foundry sand and its effect as a stabilizer on the strength of the substrate and as a stabilizer. Also, a comparison is made between the changes that occur in the base layer Cast sand treated and compared with untreated. A mixture of foundry sand with graded natural aggregate according to certain sizes is used as a stabilizer in proportions $(5,10$ and 15$) \%$. The treated and untreated base layer is compared in terms of strength. The base layer material is a traditional base material taken from the Nabaie quarry. Samples are made of three replicates of each possible group. Samples were prepared and subjected to a compressive strength CBR test. The obtained results indicate an increase in the resistance of the base material when using FS at a rate of (5\%) with a treatment period of 4 days, while a ratio of $10 \%$ gave the highest resistance in a treatment period of 14 days, and these ratios gave more resistance than the untreated samples without the additive.
\end{abstract}

Keywords: Asphalt pavements; Aggregates; Waste by products; CBR; Foundry Sand (FS).

\section{Introduction}

Pavement design is a procedure for determining the most cost-effective combination of layer thicknesses and material types as for the pavement, consideration must be given to the characteristics of the underlying soil, the resulting traffic that is transported during the supposed service life of the road, and the affecting climatic conditions .[1]

This demonstrates the economic importance of road infrastructure, as well as the amount of money invested in road development and maintenance, and the necessary need for efficient pavement design and management methods. And poorly constructed sidewalks will collapse prematurely, resulting in expensive rebuilding costs and significant economic losses.[2]

Roads are exposed to increasing pressure in their maintenance because they use recycled materials as alternative or secondary materials because they consume a large number of available materials (such as fine and coarse natural aggregates) in road construction. These materials are usually used as well as other industrial byproducts, crushed concrete aggregate and old asphalt pavement as well as rubber tires and foundry sand as additives and stabilizers that are auxiliary to natural aggregates. Since these wastes or as recycled materials are not ordinary building materials, there are concerns in terms of their environmental friendliness and whether

*Corresponding Author: edma012@uomustansiriyah.edu.iq 
they can be recycled and sustainable in road applications and road paving, and we take into account the extent of their environmental impact on the surface of the road and surface and ground water.[4]

It turns out that the unconstrained granular masses exhibit a kind of anisotropic behavior due to their random formation structure and the applied loads of the dynamic wheels. Because of its susceptibility to friction and interlocking between aggregates, loads are distributed for granular aggregates. The strength of aggregates depends largely on the cumulative effects of mechanical and physical properties of aggregated materials such as particle size distributions, geometry, shape, rough surface, size, sharp edges, and various minerals [5]

Recycled materials are used in US highway construction and selected waste material applications, including automobile tires, recycled materials, paving materials, reclaimed materials and building rubble. It is evaluated based on modern, environmental and economic techniques that these reclaimed paving materials and rubber tires have great potential to replace traditional materials used for various practical methods in highway construction and should be expected for future construction [6]

Recycled materials are used in US highway construction and selected waste material applications, including automobile tires, recycled materials, paving materials, reclaimed materials and building rubble. It is evaluated based on modern, environmental and economic techniques that these reclaimed paving materials and rubber tires have great potential to replace traditional materials used for various practical methods in highway construction and should be expected for future construction. [7]

It was found that the increase in density improves the properties of aggregates that are not bound to more sharp particles than aggregates with round particles, providing that there is no growth in the compression of the trans-pores during repeated loadings.

That these open aggregated and graded samples, when they were uncompressed, were less deformed than the densely graded samples [8] and for the lightly and strongly compressed sample, no relationship was found between the fusion stress and the classifications.

Many environmental issues may be solved by using foundry sand in many building engineering applications. Foundry sand is mostly silica sand with a thin layer of burned carbon, residue, and dust on top. Foundry sand can be used to increase the strength and longevity of pavement. It is a fine-grained by-product of the ferrous and nonferrous metal molding productions, involving of high-quality silica of even size and a high degree of cleanliness. According to the literature, sand is re-used in foundries until it becomes impossible to do so, at which point it is dumped as waste sand foundry It is at this point that roadwork is being considered. This material was used as a filler in HMA, subbase, embankments, and backfill. Its high clay percentage makes it unsuitable for areas with high water levels or poor drainage. Due to the significant volume of heavy metallic compounds, nonferrous foundries are not suggested for HMA. [9]

Foundry sand is a high-quality silica sand that is a result of ferrous and nonferrous metal castings. Mainly depends on the type of casting technique used and the manufacturing from which it is derived, both physical and chemical features of this sand. For use in moulding and casting processes, foundries buy high-quality silica sands. The crude sand is usually higher than the average bank run or the natural sands utilised in filling sites. Sand from the foundry is normally round to round. [11] 


\section{The Objective of Research}

The core objective of this paper is to estimate the result of materials and their types on core strength. Each of the primary products pre-fixed to the previous stabilizers in this foundry is sand and powder, which has performed its role in traditionally recycled the CBR test was performed to find the stress and compare it at set at $25 \mathrm{~mm}$ and $50 \mathrm{~mm}$. Two readings are taken in a rating and compared with the standard stress that was calculated in the CBR examination.

\section{Experimental Work}

The materials used in this research paper are widely available in Iraq, where they are used in road construction, foundry sand imported from Baghdad, and the industrial market in Sheikh Omar area. The work of this research paper includes two stages, the first stage of testing in the laboratory for all samples of these important basic granular materials, fixed with smelting sand, and used as secondary materials. Where three attempts are made from each set of samples at $5 \%, 10 \%$ and $15 \%$ on the method recommended in [10], [11]. Where 18 samples were prepared and subjected to moisture content, Proctor test and CBR test.

\subsection{Aggregate}

According to the Unified Soil Classification System (USCS), it can classify soils as two types of aggregate, coarse aggregate and fine aggregate.

\subsubsection{Coarse Aggregate}

Coarse aggregates range in size from passing 3/4 inch $(19.0 \mathrm{~mm})$ through into the No. $4(4.75 \mathrm{~mm})$ sieve.

Where this crushed aggregate is used in this research paper, on the other hand, all round aggregates are excluded. Whereas, the coarse aggregate is prepared from the hot mixing plant in the Taiji area, specifically Al-Nabai. The physical characteristics and chemical structure of the coarse aggregate are shown in Table 1 and Table 2 , respectively.

Table 1. Physical Properties of Nibaee Aggregates.

\begin{tabular}{|c|c|c|}
\hline Property & $\begin{array}{c}\text { Coarse } \\
\text { Aggregate }\end{array}$ & $\begin{array}{c}\text { Fine } \\
\text { Aggregate }\end{array}$ \\
\hline $\begin{array}{c}\text { Bulk Specific Gravity } \\
\text { (ASTM C127 and C128). }\end{array}$ & 2.681 & 2.6303 \\
\hline $\begin{array}{l}\text { Apparent Specific Gravity } \\
\text { (ASTM C127 and C128). }\end{array}$ & 2.602 & 2.46 \\
\hline $\begin{array}{l}\text { Percent Water Absorption } \\
\text { (ASTM C127 and C128). }\end{array}$ & 0.45 & 0.53 \\
\hline $\begin{array}{l}\text { Percent Wear (Los- } \\
\text { Angeles Abrasion) } \\
\text { (ASTM C131). }\end{array}$ & 20.12 & 20.12 \\
\hline
\end{tabular}

Table 2. Chemical Properties of Nibaee Aggregates.

\begin{tabular}{cc}
\hline Chemical Compound & Content \% \\
\hline Silica, $\mathrm{SiO} 2$ & 82.52 \\
Lime, $\mathrm{CaO}$ & 5.37 \\
Magnesia, $\mathrm{MgO}$ & 0.78 \\
Sulfuric Anhydride, SO3 & 2.71 \\
Alumina, Al2O3 & 0.48 \\
Ferric Oxide, Fe2O3 & 0.69 \\
Loss on Ignition & 6.55 \\
TSS (total soluble salts) \% & 1.9 \\
Organic matter (\%) & 0.5 \\
Gypsum content (\%) & 0.45 \\
Mineral Composition & \\
Quartz & 80.3 \\
Calcite & 10.92 \\
\hline
\end{tabular}

* Tests are carried out by NCCL

\subsubsection{Fine Aggregate}

The size limits for fine aggregates are in between size that passes through the No.4 sieve $(4.75 \mathrm{~mm})$ and the size that is retained on the No.200 sieve $(0.075 \mathrm{~mm})$. Standard specifications for base course were created by the State Corporation for Roads and Bridges in Iraq (SCRB, 2003). Table 3 and Fig. 1 illustrate the gradation utilised in this work. 


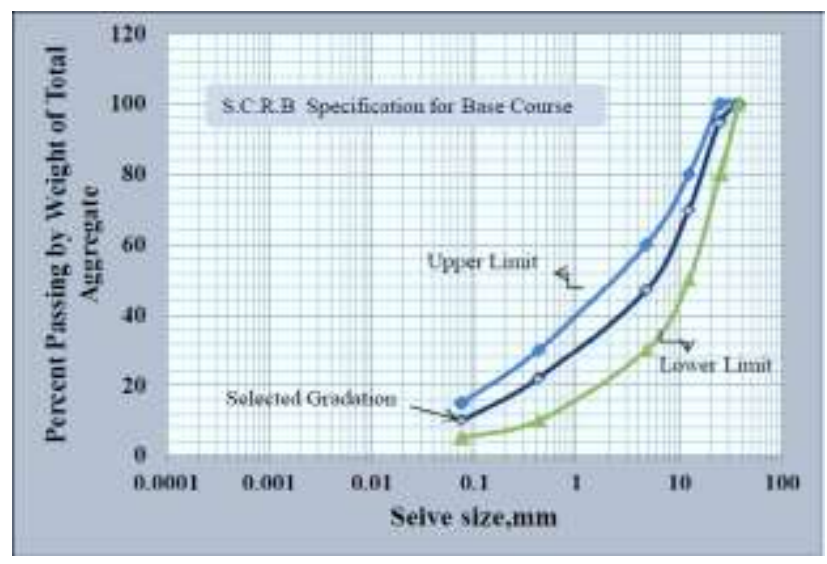

Figure 1. Specification Limits and Gradation for Base Course (SCRB, 2003).

Table 3. Gradation of the Aggregate for Base Course (SCRB, 2003).

\begin{tabular}{cccc}
\hline $\begin{array}{c}\text { Sieve } \\
\text { Size }\end{array}$ & $\begin{array}{c}\text { Sieve Opening } \\
(\mathbf{m m})\end{array}$ & $\begin{array}{c}\text { Percentage Passing by } \\
\text { Weight of total } \\
\text { Aggregate }\end{array}$ \\
\hline \multicolumn{3}{c}{ Base Course } \\
\hline $\begin{array}{c}\text { Specification } \\
\text { Limit (S.C.R.B) }\end{array}$ & Selected gradation of Aggregate \\
\hline $1_{1 / 2 "}$ & 37.5 & 100 & 100 \\
$1^{\prime \prime}$ & 25.0 & $80-100$ & 95 \\
$1 / 2^{\prime \prime}$ & 12.5 & $50-80$ & 70 \\
No.4 & 4.75 & $30-60$ & 47 \\
No.40 & 0.425 & $10-30$ & 22 \\
No.200 & 0.075 & $5-15$ & 10 \\
\hline
\end{tabular}

\subsubsection{Foundry Sand}

It is usual for the foundry sand to be of advanced quality than the typical bank sand or the natural sand used in the backfill places. Usually, the foundry sand takes a semi-angular shape to turn the form as shown in Fig.2

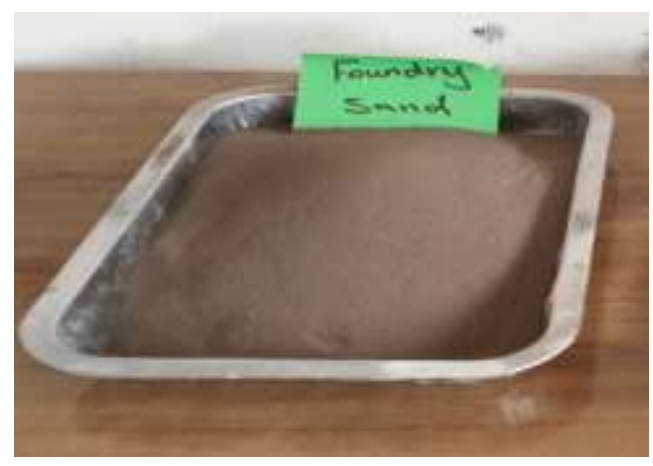

Figure 2. Foundry Sand.

\subsection{Sample of Preparation}

Sample preparation is a general term that contains all of the following:

- This determines the relative proportions of foundry sand and aggregates, as well as the percentage of each of the fractions of the total volume using this filler.

- The material (aggregate) is separated on each of the 1-in sieves. And 1/2-in. and No. 4 and No. 40 and No. 200.

- After sieving, classifying and sifting these different samples, a particle size distribution is created for each of the materials, in order to allow reestablishment of similar samples with similar gradients.

- All samples stabilized with foundry sand fume are cured for 4,14and 30 days.

- One curing temperature $\left(38 \mathrm{C}^{\circ}\right)$ for foundry sand stabilized samples.

\subsubsection{Compaction Test}

Modified compaction is used to assess the moisture density relationship for aggregate. A mold with a 6 in. internal diameter and a mechanical compaction equipment Compaction is done in accordance with (ASTM D1557) [15]. To discover OMC\&MDD, 8 samples were created of every ratio and type of stabilizing, as well as the untreated samples. Another 24 samples are generated and crushed at OMC for compressive strength testing for each stabilizer.

\subsubsection{CBR Test}

The California Bearing Ratio (CBR) test is a statistical test that was first developed in California, USA to estimate the bearing value of recycled materials in roadworks for each of the 1 weights. A force of measurement of 1 would be required to maintain this rate through the gravitypenetration relationship and that these results of the California assay (CBR value) upon examination of Attempt 1 it is important to assess 
the practical applicability of this experiment (and given its statistical nature) only to the objective that has been developed for the design of aquatic fish 1 The experiment concerned below is a standard laboratory experiment conducted on a soil-to-container model Especially known as the California Load Ratio Template The California Load Ratio (CBR) test is a penetration shear experiment at a constant rate of submersible thrust In soils at a constant rate, the required force required to maintain this rate is measured at an appropriate duration. The gravity-penetration relationship on graph paper so that the weights can be read subject to standard penetrations. The acceptable ratio is defined as percentages of standard weights 1 The acceptable ratio is defined as the California tolerance ratio or the value of the California (CBR) for soil in the case for which the test is being examined 1 The CBR value can be taken as a measure The shear resistance of the soil is not mutually exclusive but cannot be directly related to the shear resistance factors 1
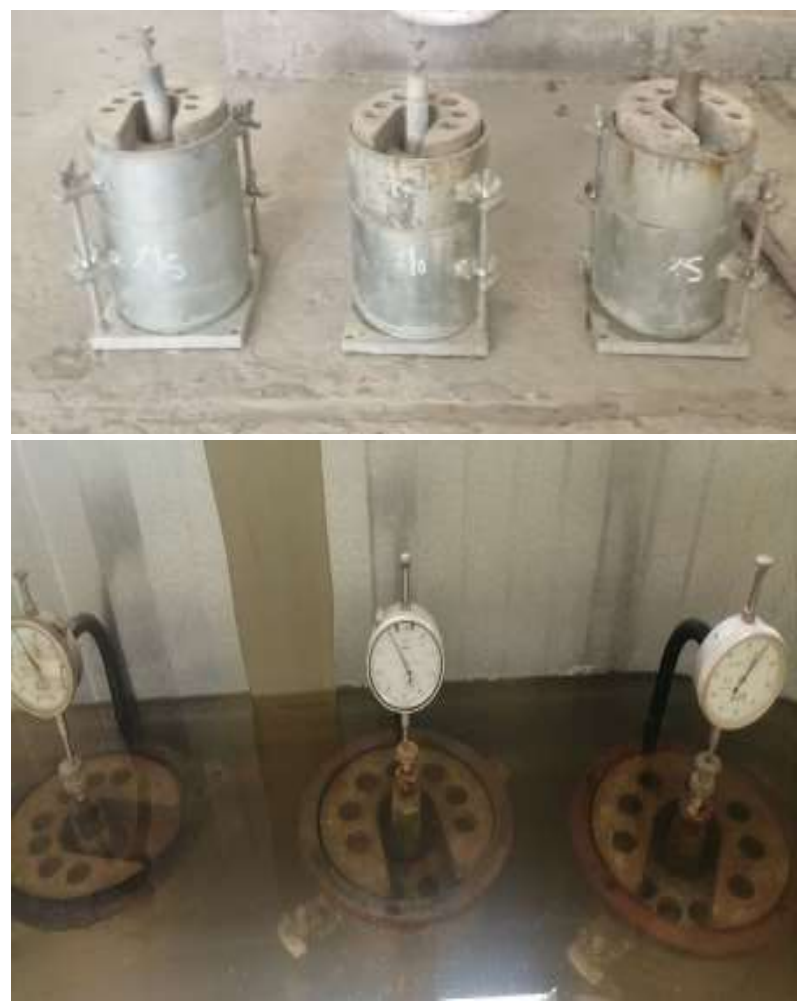

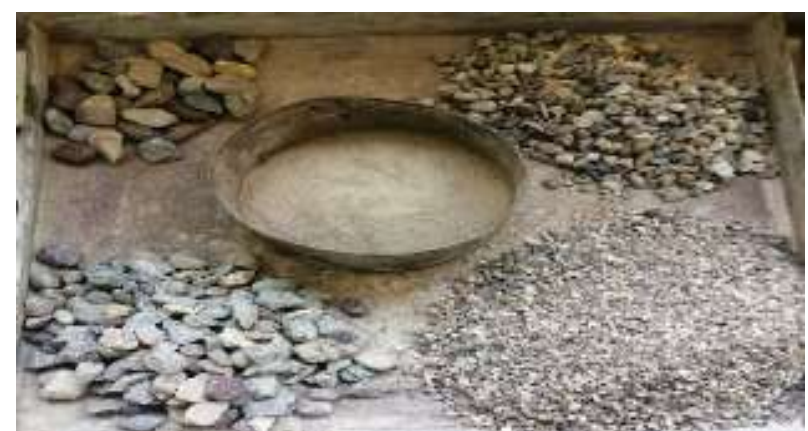

Figure 3. Illustrates preparing samples

\section{Results and Discussion}

Figure (4) shows the results of testing the effect of CBR according to ASTM D1883processing time on the strength of the base layer, when the prepared samples were processed and immersed in water for specific periods of time $(4,14,30$ days $)$ the resistance ratio increased by $(1.29 \%)$, (33.16\%) upon penetration of $250 \mathrm{~mm}$. The percentage increases $(3.50 \%)$ and $(7.395 \%)$ when penetrating $500 \mathrm{~mm}$.

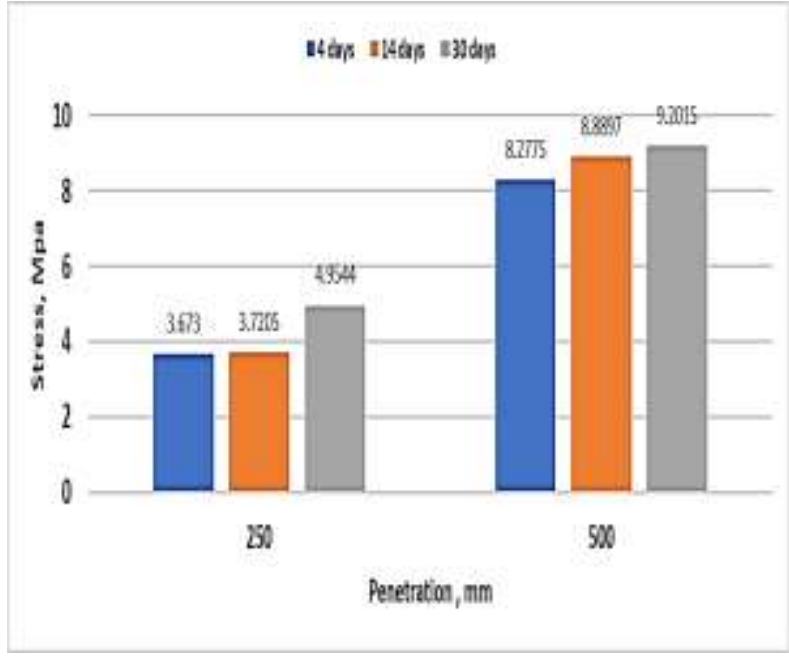

Figure 4. Illustrates preparing samples

Figure 5: shows the effect of processing time on strength of mixtures adjusted by $5 \%$ of foundry sand for the base layer. It was observed that when treating samples prepared with foundry sand in three different proportions $(5 \%, 10 \%$ and $15 \%)$ immersed in water for specified periods of time $(4,14,30$ days), the percentage of resistance increases by $(35.15 \%)$, $(85.34 \%)$ when penetrating $250 \mathrm{~mm}$, the percentage increases by $(39.72 \%),(11.74 \%)$ when penetrating $500 \mathrm{~mm}$. 


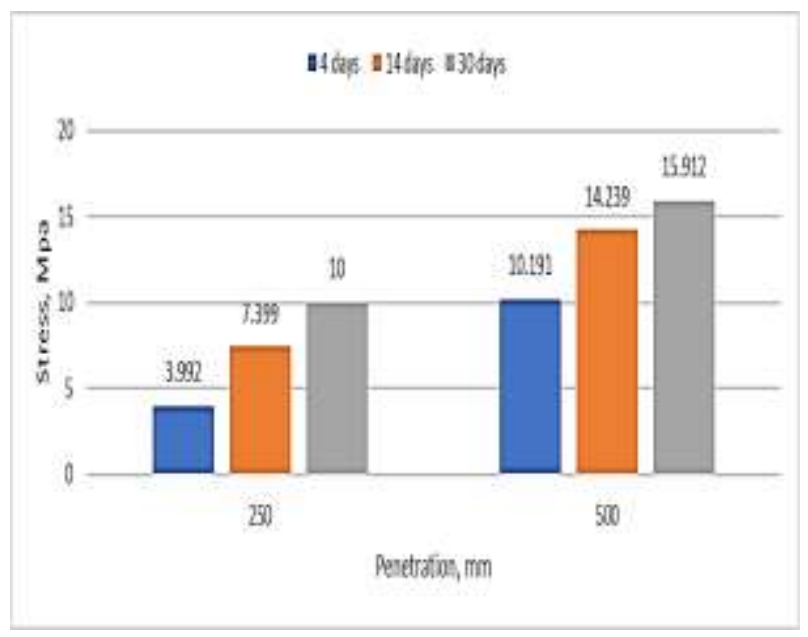

Figure 5. The Effect of Curing Duration on The Strength of Modified Mixtures by $5 \%$ of Foundry sand for Base layer

Figure 6: shows a comparison between the compressive strength of control and mixtures modified with multiple proportions of foundry sand. When the prepared samples are processed and immersed in water for a specified period of time (4 days), the resistance ratio increases by $8.7 \%, 73.2 \%$ and $1.5 \%$ when penetrating $250 \mathrm{~mm}$ where it was noticed that samples containing $10 \%$ Foundry Sand gave the highest percentage of $73.2 \%$ compared with deferent ratio, while it was noticed that when penetrating $500 \mathrm{~mm}$ increased rates of $23.1 \%, 56 \%$ and $24 \%$ and also notes that $10 \%$ of Foundry Sand gave a higher rate of $56 \%$.

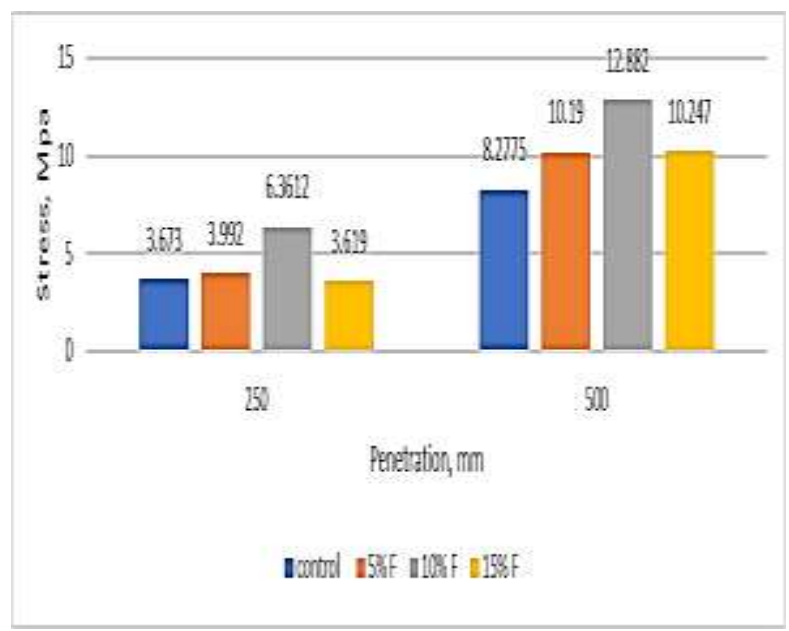

Figure 6. Illustrates preparing samples
Figure 7 shows the compressive strength of control and mixtures modified with multiple percentages of foundry sand when processing for 14 days, as it was noticed that when the percentage of Foundry Sand increased, the percentages gradually decreased $98.8 \%, 86 \%, 34.5 \%$, and $5 \%$ of Foundry Sand gave the highest percentage. When penetrating $250 \mathrm{~mm}$, while when penetrating $500 \mathrm{~mm}$, the resistance values decrease by $60.2 \%, 54.2 \%, 26 \%$. We also note that the 5\% Foundry Sand percentage gave the highest percentage compared to other ratios



Figure 7. The Compressive strength of Control and Modified Mixtures by Several Percentage of Foundry Sand at Curing of 14 Days.

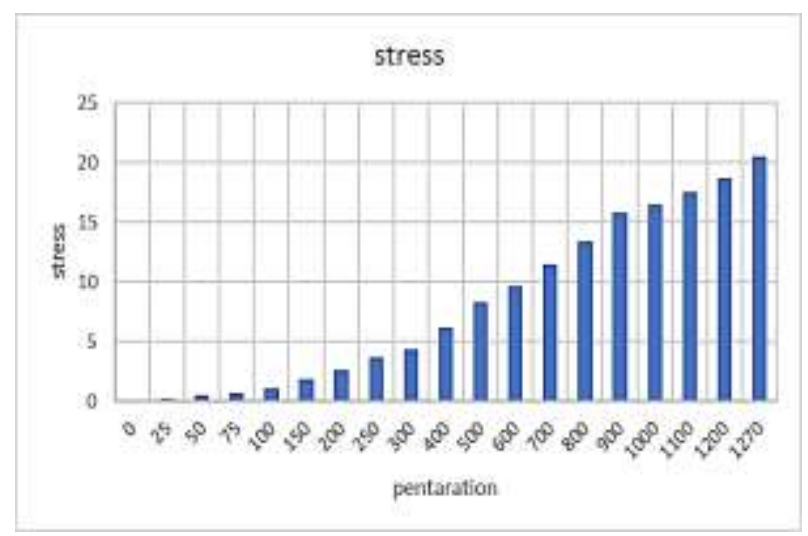

Figure 8. CBR mold sunken in water for 4 days without additives. 


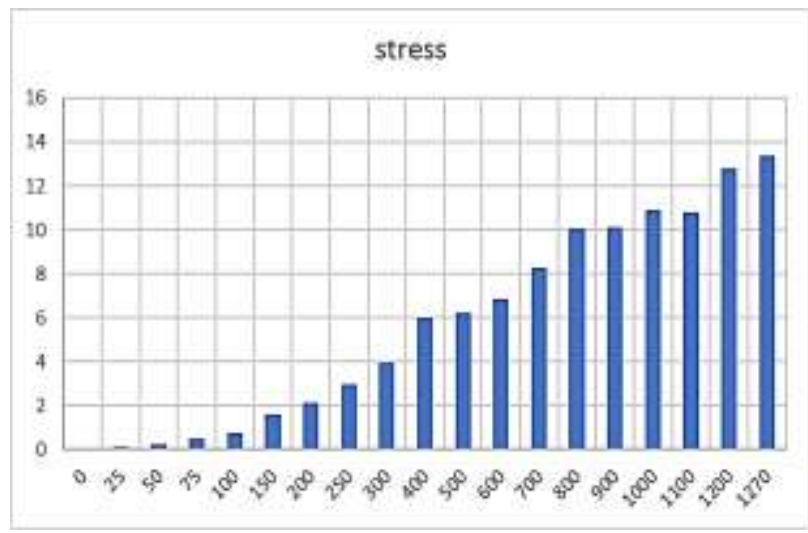

Figure 10. 30 days old without additives.

As noticed from figures, 14 days old without additives has the highest stresses of penetrations 500,250

\section{Conclusions}

From the research investigation, the following major findings may be gathered as shown:

1- Foundry sand is suggested as an excellent long-term material for pavement construction.

2- The basic material treated with foundry sand (FS) at a rate of 5\% gave the best stress resistance with a treatment period of 4 days, and a percentage of $10 \%$ of (FS) gave the highest stress resistance in the treatment period of 14 days.

3- Pavement with a foundry sand-treated base layer reduces distresses and thus longer pavement design life is maintained.

4- This research can help to decrease the environmental consequences of trash and waste disposal issues..

5- After getting the laboratory results at the age of 30 days, it was found that the results of the percentages are as follows (5\% is $40.9 \%, 10 \%$ is $57.53 \%$, and $15 \%$ is $44.33 \%$ ).

\section{Acknowledgements}

The researchers would like to express their gratitude to Mustansiriyah University's Faculty of Engineering, Road and Transport Department, for their support and advice in completing this research's modest paper. In the content of this research, no specific funds were obtained from supporting organisations, commercial, or notfor-profit sectors.

\section{Conflict of Interest}

The authors confirm that the publication of this article causes no conflict of interest.

\section{References}

1. Araya A A 2011 "Characterization of Unbound Granular Materials for Pavements"

2. Masood G 2013 "Experimental and Numerical Investigation of Stabilized Unbound Granular Pavement Materials" AL-Mustansiriyah University College of Engineering Highway and Transportation Engineering Department MSc Thesis. Thesis)

3. AL-Kaissi Z A, Jabbar,A.\&Ghada,G.M. (2014) "Effect of Materials and Stabilizers Type on the Strength of Base Layer" Journal of Engineering and Devlopment,vol.18,no.5

4. Farhan A H, Eng B S C and Eng A 2016 "Characterization of Rubberized CementStabilized Roadbase Mixtures". University of Nottingham)

5. M and Ashtiani R S J T G 2018 "Stability Analysis of Anisotropic Granular Base Layers in Flexible Pavements" 14 183-9

6. Ahmed M 1991 "A Model to Determine Benefits Obtainable from The Management of Riverine Fisheries of Bangladesh" vol 728: WorldFish)

7. AL-Kaissi Z A, Jabbar,A.\&Abdulhassan E.(2016) "Evaluation The Performance Of Treated Base Layer On Critical Responses Of Flexible Pavement" Journal of engineering and sustainable development,vol.20,no.5.

8. Thom N and Brown S 1988 The effect of grading and density on the mechanical properties of a crushed dolomitic limestone. In: Australian Road Research Board (ARRB) Conference, 14th, 1988, Canberra,

9. Siddique R, Noumowe A J R, "Conservation and Recycling 2008 Utilization Of Spent 
Foundry Sand in Controlled Low-Strength Materials and Concrete" 53 27-35

10. EMAN A. MOHAMMED 2006 "Effect of Leaching on Granular Materials On Performance of Flexible Pavement". A Thesis Submitted to the Highway and Transportation Engineering Department College of Engineering AL-Mustansiriya University

11. Kassim, T. A., Simoneit, B. R., \& Williamson, K. J. (2005). "Recycling Solid Wastes as Road Construction Materials: An Environmentally Sustainable Approach. in Water Pollution” (pp. 59-181). Springer, Berlin, Heidelberg. 